\title{
Effect of organizational role stress on organizational culture: evidence from service-sector
}

\author{
Pretty Bhalla \\ Lovely Professional University, Jalandhar, India \\ Sayeeduzzafar Qazi \\ Maram Saleh Miralam \\ College of Business Administration \\ University of Business \& Technology, Jeddah, Saudi Arabia
}

Key Words

Autonomy, Personal Inadequacy, Pro-Action, Role Erosion, Trust.

\begin{abstract}
Service sector is dominantly the largest sector in India and to maintain the current position of Rank 11 in the World Service Sector, Organizational culture of every Indian organization plays a very critical and crucial role. It determines the Accelerated or retardate growth of the organization. Culture acts as an invisible adhesive that holds values, technology adoption, working parameters intact which are the essence of organization's existence. Culture also acts as creator of organizational stress and the increasing stress level among employees reduces effectiveness and efficiency or individual and organization as a whole. Various research work states culture creates stress but does stress effect culture? The objective of the study was to examine the impact of Organizational Role Stress on OCTAPACE Culture and recommend proper interventions to stake holders for reducing the organizational role stress and make better OCTAPACE Culture in the service sector. The present study was conducted on 474 employees of organized Retail and Telecom service sectors randomly drawn using questionnaire method. The result indicates that negative correlation exists between Organizational role stress and organizational Culture.
\end{abstract}

Corresponding author: Sayeeduzzafar Qazi

Email addresses for the corresponding author: sayeedz@yahoo.com

First submission received: $4^{\text {th }}$ May 2018

Revised submission received: $3^{\text {rd }}$ August 2018

Accepted: $22^{\text {nd }}$ October 2018

\section{Introduction}

Service sector is not just the largest in India, but the entire world stands by to prove the same. For the ever-increasing service sector to have exponential growth or to have bare minimum survival, a stressfree culture should be developed for the organization existence. In an organization, stress can be defined as variance between abilities and skills of an individual and what his job demands. As per French, Rogers \& Cobb, 1974 as a misfit when a person's job environment is insufficient to fulfill his needs. In 1975 Caplan et al. explained organizational stress and said that if any threat is posed to an individual due to his job environment then it can be termed as organizational stress. Under role stress, a specific type of stress is considered. Kahn et al. (1964) expressed the difference between stress and various role stresses. Role stress includes other constructs under it such as: Role conflict, ambiguity, and overload. Basically, role stress occurs when an individual lack with recourses and capabilities to meet job expectations. Role conflict can be said to occur when there are conflicts over expectations. Some of the variables which relate to individual's role are not compatible with each other. These incompatibilities result in serious consequences. The role stress was classified under 3 categories by "Kahn and Quinn (1970) (a) Expectation which generates stress- dimensions are role conflict and role ambiguity (b) Expectation resource discrepancies- dimensions are role overload, authority dilemma, inadequate technological information and responsibility (c) Personality and Role". 
Role space conflicts: The interrelation between various roles and responsibilities which an individual have and plays is called role space. It can be categorized into three important variables: individual, the role which is under object, and the other roles an individual have. Following are the forms which may take place because of role space conflict are Self-Role Distance, Role Stagnation, Inter-Role Distance.

Role set conflicts: When several roles may conflict with one another or a single role may carry conflicting duties and pressures. "The conflicts which arise as a result of incompatibility amongst the expectations because of various roles an individual play, or more individual playing the same roles, it is called role set conflicts" (Pareek. 1983). These conflicts can be discussed under following heads:Role Ambiguity (RA), Role Expectation Conflict (REC), Role Overload (RO), Role Erosion (RE), Resource Inadequacy (RIn), Personal Inadequacy (PI), Role Isolation (RI), Self - Role Distance (SRD), Resource Inadequacy (RIN), Role Stagnation (RS)

\section{OCTAPACE Culture}

Culture can be understood as the land on which plants grow, more fertile or handled properly, the land proves the same with the crop yield. Similarly, organizational culture is the platform on which organization grows, if handled properly it would yield exponential profits. Organizational culture is a set of various values and behaviors that builds a social and psychological environment of any organization. According to Schein (1992) "Organizational culture is the "basic assumptions and beliefs that are shared by members of the organization. Culture is considered as an internal variable meaning that it is something that organization has." Organizational culture includes "an organization's expectations, experiences, philosophy, and values that hold it together, and is expressed in its self-image, inner workings, interactions with the outside world, and future expectations and it is based on shared attitudes, beliefs, customs, and written and unwritten rules that have been developed over time and are considered valid". Denison (1990) "Refers to the underlying values, beliefs and principles that serve as a foundation for an organization's management system as well as the set of management practices and behaviors that both exemplify and reinforce those basic principles."

Department of Human Resource in every organization has given a huge consideration to development of right kind of Culture in an Organization. Organization Culture can be defined as OCTAPACE which can be elaborated as openness, confrontation, trust, authenticity, pro-activity, autonomy, collaboration and experimentation. These parameters play a crucial role in developing culture of the organization. The eight attributes are discussed as below:

Openness: An Organization which accepts and experiments new ideas take risks and are more focused towards developing innovative ideas. Even the employees have the liberty to communicate freely their thought process and ideas.

Confrontation: An Environment in which people work together, face problems together and finds a solution for it. They openly face issues, without hurting or avoiding others

Trust: It is an intangible aspect that makes a strong organization base where the employees and employers have a sense of honor, shoulders responsibility, keep confidentiality and are accountable for the task they perform.

Authenticity: it shows the direct correlation between what an individual says and feels, does the work and owes its responsibility and accountability, its other words it can be defined as being transparent with what ones says and does in organization.

Proactivity: It is the developed environment in the organization which encourage employees to take initiative and preplan by forecasting future needs and problems.

Autonomy: An environment in which employee uses their power and position without any fear and help other. It refers to the freedom to take decision within framework of assigned responsibilities.

Collaboration: It is an aspect which defines that all employees unite and work together for achieving organizational objective. The environment is categorized as problem solving and harmonious

Experimentation: it refers to the organizational practices of innovative for problem solving; feedback is considered as a source of improvement, various working styles and perspectives of problem solving are accepted and appreciated. 


\section{Objectives}

1.) To examine the level of Organization Role Stress and Organization Culture in service sector.

2.) To examine the relationship between Organizational Culture and Organizational Role Stress.

3.) To offer suitable suggestions to stake holders for reducing Organizational Role Stress and develop better Organizational Culture in service sector.

\section{Literature Review}

The stress is widely researched topic and various studies from different sectors have shown the stress level above the marginal points, like faculty members of public or private institutes experience high level of stress and dominant factor is role overload(Bhalla, 2013).Role overload occurs when faculty is assigned increased work responsibility (academic and administrative).Monotonous work of faculty members of interacting with students, changing demands of industry and requirement of superiors is responsible for crossing stress levels and increasing dissatisfaction, absenteeism (Saberwal 2015). Role conflict and role ambiguity also leads to stress which in result reduces motivation, productivity and efficiency in organization. (Conley \& Woosley, 2000; Koustelios et al, 2004; Nwadiani, 2006; Chang and Lu, 2007). Role conflict is the result of various expectation which are pinned on an individual from number of sources(Nazneen et al 2014).research shows that the organizational culture holds a strong impact on individual and organizational satisfaction (Zafar et al 2017) Another study proves that if organizational culture is good, employees remain more committed and a good positive impact is on profitability of organization and most important parameters which effect culture are Confrontation, openness, experimentation and proactively (Bhalla et al 2014). It is found that is no significant difference between male and female employees in terms of total stress levels and has almost similar job satisfaction levels (Nazneen, 2013). Stress can originate because of number of reasons like shifting to new place (Larson, 2004; Chang and Lu, 2007), working in huge organization with various hierarchical levels, lack of effective communication (Gmelch and Burns, 1994; Larson, 2004). Bhalla et al (2013) found that top level executives in both public and private sector enterprises faces comparatively less stress to lower and middle level mangers based on research conducted on 350 employees.

Nazneen \& Bhalla (2013) studied stress level in organized retail sector of India and found that males are more stressed as compared to females' counterparts and proved that negative correlation exist between commitment and stress level. The recent survey suggests that nearly 91.5 million working days are lost each year due to stress ((Smith, 2000). Because of high stress level of organizational employees, the dimension which are hard hit, which leads to create negative organizational culture are decreased efficiency and effectiveness, no acceptance to change or new technology, lack of apprehension for organization and colleagues and lack of accountability. But the literature carrying evidence that if stressed individual is associated with the organization, would it have impact on change of organizational culture. The correlation among organizational culture, stress and commitment was significant. They further concluded that to determine appropriate culture of any organizations is a very complex task as it is based on varied dimensions of organizational structure functions, equalities, inequalities, values, beliefs, mission and vision (Monga et al 2015)

\section{Methodology: Samples}

Considering the current sector and accessibility of the individuals for data collection the current study was done on 495randomly selected employees of various organized service sector spread in northpart of India. After checking the filled data 21questionnaires were not accepted as the information provided was inadequate. The rest 474 people data were considered for the research. The respondents were categorized demographically on basis of gender, education, designation etc.

\section{Tools used}

Questionnaire method was used for the current research using two standardized psychometric measures and the details of them are as follows:

OCTAPACE profile which was developed by Pareek and Rao (1993), having 40 item instrument which gives profile of organizational ethos in 8 values was used in the study. 
Through this questionnaire respondents can check actual and desired or ideal profile of an employees required by organization. The reliability and validity of the scale is within acceptable norms. RS is a five-point scale (0-4), containing five items for each role stress and a total of 50 statements.

\section{Procedure}

Data was collected by survey method from respondents with more than two years of experience. The respondent from each organization was provided with intent letter for the purpose of research and access. Once permission was granted, the questionnaires with a participant information sheet were distributed in either electronic form or in hardcopy to employees. They were asked to properly go through the instructions and fill the form at the workplace itself

\section{Results and Discussion}

Table 1: Showing Mean scores of the overall employees of service sector on the dimension of ORS $(\mathrm{N}=474)$.

\begin{tabular}{|l|l|l|}
\hline Parameters & Mean & SD \\
\cline { 1 - 1 } Inter Role Distance & 6.82 & 2.51 \\
\cline { 1 - 1 } Role Stagnation & 6.99 & 2.34 \\
\hline Role Expectation Conflict & 7.49 & 4.06 \\
\cline { 1 - 1 } Role Erosion & 9.08 & 3.78 \\
\hline Role Overload & 7.44 & 3.42 \\
\hline Role Isolation & 6.73 & 3.79 \\
\cline { 1 - 1 } Personal Inadequacy & 7.92 & 3.27 \\
\cline { 1 - 1 } Self-Role Distance & 7.91 & 4.94 \\
\hline Role Ambiguity & 5.66 & 3.70 \\
\cline { 1 - 1 } Resource Inadequacy & 6.43 & 3.57 \\
\hline Organizational Role Stress & 73.50 & 25.45 \\
\hline
\end{tabular}

It is evident from the Table 1 that the employees of service sectors are having moderate level of organizational role stress and leading stressors are Personal Inadequacy, Self- Role Distance, Role Erosion , Role Expectation Conflict, and Role Stagnation respectively contrary to the findings of Bhalla et al (2013) in their study on 350 top officials of public and private revealed that top officials of private sectors are demonstrate extraordinary high ORS and the prevailing stressors were "role erosion, role isolation and inter role distance" whereas in public unit enterprises, the stress level was found moderately high among top executives, however dominant stressors were similar to that of private enterprises.

Table 2: Showing Mean scores of the overall employees of service sector on the dimension of Organizational Culture $(\mathrm{N}=474)$.

\begin{tabular}{|c|c|c|}
\hline Parameters & Mean & Std. Deviation \\
\hline Openness & 12.51 & 1.95 \\
\hline Confrontation & 12.52 & 1.89 \\
\hline Trust & 11.75 & 1.90 \\
\hline Authenticity & 12.24 & 2.19 \\
\hline Pro -Action & 11.88 & 2.82 \\
\hline Autonomous & 11.63 & 2.08 \\
\hline Collaboration & 11.75 & 2.34 \\
\hline Experimentation & 12.55 & 2.19 \\
\hline Organization Culture & 96.83 & 9.36 \\
\hline
\end{tabular}

The employees of service sectors are experiencing moderate level of organizational culture and dominant factors includes Experimentation refers to the organizational encouragement to innovative 
problem solving; feedback is considered as a source of improvement, various working styles and perspectives of problem solving are accepted and appreciated. Confrontation means. Positive work environments can be reinforced through just organizational policies and strategies that have been found to reduce and alleviate workplace stress (Faragher et al., 2004).

Table 3: $\mathrm{CR}$ analysis of the Male $(\mathrm{N}=305)$ and Female $(\mathrm{N}=169)$ employees of service sector for the scores on the dimension of ORS.

\begin{tabular}{|c|c|c|c|c|}
\hline Parameters & Gender & M & SD & CR Value \\
\hline \multirow[t]{2}{*}{ Inter Role Distance } & Male & 7.42 & 2.98 & \multirow[t]{2}{*}{1.01} \\
\hline & Female & 7.12 & 3.38 & \\
\hline \multirow[t]{2}{*}{ Role Stagnation } & Male & 7.76 & 31.8 & \multirow[t]{2}{*}{1.23} \\
\hline & Female & 7.38 & 3.24 & \\
\hline \multirow[t]{2}{*}{ Role Expectation Conflict } & Male & 7.47 & 3.36 & \multirow[t]{2}{*}{0.06} \\
\hline & Female & 7.49 & 4.25 & \\
\hline \multirow[t]{2}{*}{ Role Erosion } & Male & 9.47 & 3.43 & \multirow[t]{2}{*}{$2.37^{* *}$} \\
\hline & Female & 8.67 & 3.64 & \\
\hline \multirow[t]{2}{*}{ Role Overload } & Male & 7.58 & 3.45 & \multirow[t]{2}{*}{0.90} \\
\hline & Female & 7.29 & 3.17 & \\
\hline \multirow[t]{2}{*}{ Role Isolation } & Male & 6.83 & 3.53 & \multirow[t]{2}{*}{0.55} \\
\hline & Female & 6.65 & 3.24 & \\
\hline Personal Inadequacy & Male & 8.74 & 3.15 & $5.41^{*}$ \\
\hline \multirow[t]{2}{*}{ Self-Role Distance } & Male & 8.92 & 3.12 & \multirow[t]{2}{*}{$6.60^{*}$} \\
\hline & Female & 6.92 & 3.23 & \\
\hline \multirow[t]{2}{*}{ Role Ambiguity } & Male & 6.21 & 3.14 & \multirow[t]{2}{*}{$3.48^{*}$} \\
\hline & Female & 5.12 & 3.46 & \\
\hline \multirow[t]{2}{*}{ Resource Inadequacy } & Male & 6.74 & 3.32 & \multirow[t]{2}{*}{1.88} \\
\hline & Female & 6.13 & 3.47 & \\
\hline \multirow[t]{2}{*}{ Organizational Role Stress } & Male & 77.14 & 22.38 & \multirow[t]{2}{*}{$3.31^{*}$} \\
\hline & Female & 69.87 & 23.65 & \\
\hline
\end{tabular}

*Significant at 0.01 level of significance

This states that "high level of organizational role stress than their female counterparts and the difference is significant at .01 level of significance". Significant difference of mean was also found on the dimension of role erosion, personal inadequacy, self-role distance and role ambiguity. No significant difference of means was observed on the remaining dimensions of organizational role stress, in contrast to findings of Nazneen \& Bhalla (2013) who surveyed 218 male and 132 females' service employees in Punjab, India, and found that male and female both face same level of ORS.

Male employees are face high level of role erosion than female employees of service sector, this could be attributed to male employee perception that their roles has been eroded by someone in contrast to female staff because in service sector it is said that it is difficult for the female to survive because of long working hours and other related issues. While on the dimension of self-role distance again the male employees have high level of stress as they believe that they are doing lot of activities that they are not supposed to do. During the data collection it was reported by majority of the staff that they were asked to do even those things that they are not supposed to do, and female staff are willing to do any job assigned to them. Hence felt less stressed on this dimension. While on the dimension of role ambiguity significant difference of mean were observed between male and female staff. And male staff is showing high level of Stress than female staff. It means male employees are not clear about their role that they are supposed to perform and were asked by the organization to perform job which are different every time and hence creating an ambiguity in the role to perform, while female employees are taking otherwise and ready to 
perform all duties and responsibilities allocated to them because of their very minimal presence in the service sector and the same time they have to prove that they fit to be part of this upcoming sector.

Table4: Correlation Analysis between the dimensions of Organizational Culture and ORS.

\begin{tabular}{|c|c|c|c|c|c|c|c|c|c|c|c|}
\hline Parameters & IRD & SRD & REC & RE & $\mathrm{RO}$ & RI & PI & SRD & RA & RIN & ORS \\
\hline Openness & $-.097^{*}$ & $-.183^{* *}$ & $.289^{* *}$ & $-.156^{*}$ & $.228^{* *}$ & $-.334^{* *}$ & $-.319^{* *}$ & -.039 & $-.421^{* *}$ & $-.320^{*}$ & $.351^{* *}$ \\
\hline Confrontation & $-.155^{* *}$ & $-.234^{* *}$ & $356^{* *}$ & $164^{* *}$ & $412^{* *}$ & $344^{* *}$ & $-.348^{* *}$ & $-.149^{* *}$ & $-.387^{* *}$ & $-.219^{* *}$ & $.427^{* *}$ \\
\hline Trust & $-141^{* *}$ & $-271^{* *}$ & $.278^{* *}$ & $.292^{* *}$ & $472^{* *}$ & $.371^{* *}$ & $-332^{* *}$ & $.222^{* *}$ & $-.357^{*}$ & $-.228^{* *}$ & $-434^{*}$ \\
\hline Authenticity & $-191^{* *}$ & -.035 & -.037 & $.324^{* *}$ & $195^{* *}$ & $249^{* *}$ & $-.218^{* *}$ & -.017 & $-182^{* *}$ & $-.289^{* *}$ & $.237^{* *}$ \\
\hline Pro -action & $-.320^{* *}$ & $-.261^{* *}$ & {$\left[145^{* *}\right.$} & $.219^{* *}$ & $437^{* *}$ & $-.305^{*}$ & $-.230^{* *}$ & $-.127^{* *}$ & $-302^{*}$ & $-.277^{* *}$ & $-387^{*}$ \\
\hline Autonomous & .017 & .045 & $232^{* *}$ & $139^{* *}$ & $121^{* *}$ & -.056 & -.040 & $128^{* \star}$ & $.234^{* *}$ & $101^{* *}$ & $.133^{* *}$ \\
\hline Collaboration & .031 & .001 & $232^{* *}$ & $126^{* *}$ & -.019 & $141^{* *}$ & -.067 & -.021 & .059 & $-192^{* *}$ & $-114^{* *}$ \\
\hline Experimentat ion & $-.148^{* *}$ & $-102^{*^{*}}$ & $\begin{array}{l}-273^{*} \\
* *\end{array}$ & -.021 & $-156^{*}$ & $-273^{* *}$ & $-.218^{* *}$ & -.023 & .016 & $.209^{* *}$ & $.214^{* *}$ \\
\hline $\begin{array}{l}\text { Organization } \\
\text { Culture }\end{array}$ & $-.255^{* *}$ & $-243^{* *}$ & $-326^{* *}$ & $-262^{* *}$ & $.414^{* *}$ & $-.467^{*}$ & $-.411^{*}$ & $-.113^{* *}$ & $-.309^{*}$ & $-.389^{*}$ & $.448^{*}$ \\
\hline
\end{tabular}

The result shows that "Organizational culture has very strong negative correlation with organizational role stress which were found to be significant at .01 level of significance means if the organization will provide a good organizational culture the level of organizational role stress will be low". In another words if the organizational culture goes up or conducive and harmonious the level organizational role stress will go down

The results also state that there does exist a significant negative correlation between the dimensions of organization culture and dimension of organizational role stress. Means if the organizational culture is conducive and harmonious as it is evident from the results the organizational role stress will also not increase and employees will not face any problem related with stress which leads to lot many medical disorders and hence will be productive in the organization.

\section{Discussion}

Service industry would never see the setting sun till existence of human race, reason is simple because humans cannot live without food, clothing and shelter and communication or social interactions. The first objective of this study is to examine the level of Organization Role Stress and Organization Culture in service sector. The results indicate that the service employees face moderate extent of organizational role stress, with average score on dimension- inter role distance, role stagnation, role expectation conflict, role overload, self-role distance and overall organizational role stress .High score on dimensions of Role Erosion and Personal Inadequacy and low score on dimensions of role isolation, Role ambiguity and Resource Inadequacy. On the dimension of organizational culture again the score indicates moderate level, with higher extent of score on parameters of Openness, Confrontation, Proaction, Collaboration and Experimentation whereas average score on parameters of Trust, Authenticity and Autonomy.

It is further investigated that Male employees in service sector are found to be more stressed in comparison to females and the dominant parameters are Role Erosion, Personal Inadequacy and Self Role Distance. The results further reveal that the male employees find that the organizational culture to be moderately supporting and the key parameters are Openness, Confrontation, Pro-action, Collaboration and Experimentation. In comparison to male employees' female employees are comparatively lesser stressed and enjoy their work. Female employees also find the organizational culture to be moderately supportive than male employees. 
Second objective is to examine the relationship between Organizational Culture and Organizational Role Stress. With the help of correlation, we tried to find out relationship between organizational culture and organizational role stress. It was observed in the study that the organizational culture and organizational role stress and its components are having negative significant correlations among each other.

It is suggested that service sector should do periodic Stress Audit Survey so that the prevailing stressors can be identified, and remedies can be suggested as either organizational interventions or employee interventions. To improve the organizational culture "it is the responsibility of the Leadership to work on the missing OCTAPACE factors and must increase autonomy, trust and authenticity by using various OD interventions".

\section{Conclusion}

Stress is the main hindrance of employee commitment and satisfaction, which leads to negative culture in organization which ultimately leads to lower productivity and profit. If we want our organization to stand high, main thing to focus is stress causing elements which are depleting our organization culture

\section{References}

Bhalla.P\& Zafar, S (2013), "A study of ORS and Organizational Commitment in Organized Service Sector", Research Journal of Economics and Business Studies with ISSN No 2251-1555. Sept. 2013.

Caplan, R.D; and Jones, K.W. (1975), "Effects of Workload, Role Ambiguity and Types; A Personality on Anxiety, Depression and Heart Rate", Journal of Applied Psychology, 60(b), pp. 713-719

Chang, K., Lu, L. (2007). Characteristics of organizational culture, stressors and wellbeing: The case of Taiwanese organizations. Journal of Managerial Psychology, 22(6):549-68

Conley, S., \& Woosley, S. A. (2000). Teacher role stress, higher order needs and work outcomes. Journal of Educational Administration, 38, 179-201.

Denison, D.R. (1990), “Corporate Culture and Organizational Effectiveness", New York, John Wiley \& Sons.

Faragher, E.B., Cooper, C.L. and Cartwright, S. (2004): "A shortened stress evaluation tool (ASSET)", Stress and Health, 20(4), pp. 189-201.

French, J. R. P., Jr., Rodgers, W. L. and Cobb, S. (1974). 'Adjustment as person- environment fit'. In: Coelho, G.,

Hamburg, D. and Adams, J. (Eds) Coping and Adaptation, Basic Books, New York, pp. 316-333.

Gmelch, W. H., \& Burns, J.S. (1994). Sources of Stress for Academic Department Chairpersons. Journal of Educational Administration, 32(1):79- 94

Kahn, R. L., Wolfe, D. M., Quinn, R. P., Snoek, J. D., \& Rosenthal, R. A. (1964). Organizational stress: Studies in role conflict and ambiguity. New York: Wiley

Kahn, RL and Quinn, R.P. (1970): “Role Stress-A framework for analysis" in A.A. McLean Eds. Mental Health and Work Organization, pg. 50-115, Chicago: Rand McNally.

Koustelios and Kousteliou, 2004 Relations among measures of job satisfaction, role conflict, and role ambiguity for a sample of Greek teachers. Psychological Reports, 82, 131-136.

Larson, L.L. (2004). Internal auditors and job stress. Managerial Auditing Journal, 19(9):1119-130.

Monga, O.P., Monga, A., Mahajan, V., Monga, A. (2015): “Organizational Culture, Stress and Commitment: A Study of Managers of Pharmaceutical Industry in Himachal Pradesh", Open Access Library Journal.

Nazneen, A\&Bhalla, P. (2013), "A Comparative Study of ORS and Job satisfaction among male and female employees of Organized Service Sector", International Journal of Business Management and Research" vol3, Issue 4 pp 1928.

Nazneen, A\& Bhalla, P. (2013), “A Study of Organizational Role Stress in Indian Service Sector", International Journal of Management Research and Reviews Vol 3/Issue 7.

Nazneen, A\&Bhalla, P. (2014), "A study of ORS and among the Faculty members of Private and Public University", International Journal of Human Resource Management and Research, vol 3 issue 4 pp-17-25.

Nwadiani, M. (2006). Level of perceived stress among lectures in Nigerian universities. Journal of Instructional Psychology, Retrieved June 2, 2008,

Pareek, U (1993), “Making Organizational Role Effective”, Tata McGraw Hill Publishing Company Ltd, New Delhi.

Pareek, U. (1983): "ORS Scale: Measuring Role Stress(mimeo)", Indian Institute of Management, Ahmedabad.

Sabherwal, N., Ahuja, D., George, M., Handa, A. (2015): "A study on occupational stress among faculty members in Higher Education Institutions in Pune", SIMS Journal of Management Research, 1, pp. 18-23. 
Schein, E. H. (1992): “Organizational culture and leadership (2nd ed.)”, San Francisco, CA: Jossey-Bass.

Smith, A. (2000). The scale of perceived occupational stress. Journal of Occupational Medicine, 50(5):294-98.

Zafar, S. Q., Miralam, M.S. and Bhalla, P. (2017): “Organizational culture and job satisfaction: a studyOf organized service sector." Journal of Business and Service Management Research (JBRMR), Vol. 12 Issue 1, pg. $215-224$.

Zafar, S.Q. and Nazneen, A. (2016): "A Comparative Study of Organizational Role Stress and Organizational Commitment Among the University Faculty Members of India and Saudi Arabia." European Scientific Journal November 2016 edition vol.12, No.31, pg. 108-127 